\title{
Foraging strategy of a tropical seabird, the red- footed booby, in a dynamic marine environment
}

\author{
Henri Weimerskirch ${ }^{1,3, *}$, Matthieu Le Corre ${ }^{2}$, Sébastien Jaquemet ${ }^{2}$, Francis Marsac $^{1}$ \\ ${ }^{1}$ IRD, Centre de la Réunion, UR 109 Thetis, BP 172, 97492 Sainte Clotilde, Ile de la Réunion, France \\ ${ }^{2}$ Laboratoire d'Ecologie Marine, Université de la Réunion 15 avenue René Cassin, BP 7151, 97715 Saint Denis, \\ Ile de la Réunion, France \\ ${ }^{3}$ Present address: Centre d'Etudes Biologiques de Chizé, CNRS, 79360 Villiers en Bois, France
}

\begin{abstract}
The foraging behaviour of animals depends on the distribution, abundance and predictability of their food resources. In the marine environment, top predators such as seabirds are known to concentrate their foraging effort in specific oceanic features where productivity is elevated or prey concentrated. When marine productivity is low and prey distribution unpredictable, such as in tropical waters, selection should favour the evolution of flexible foraging strategies. By using GPS, Argos transmitters and activity recorders, we studied the foraging strategy of red-footed boobies (RFBs) Sula sula breeding on Europa Island in the Mozambique Channel, to examine the way a central place forager searches for prey in tropical waters. RFBs only foraged during the day-time and never sat on the water at night; thus, they consequently had a limited maximum foraging range of $148 \mathrm{~km}$. Primary production within this range was low overall (average $0.165 \mathrm{mg}$ chlorophyll $\mathrm{m}^{-3}$ ), with a high spatial and temporal heterogeneity due to the presence of strong geostrophic currents and surface mixing by storms. RFBs appear to adjust their foraging strategy to cope with this situation. Individual birds do not return to the same oceanic sites from one trip to the next, but generally head in the direction of zones where productivity is enhanced. Active foraging, i.e. periods when birds spent time on the sea surface or dived, occurred at the most distant part of the foraging trip. Despite their limited foraging range and the low productivity of surrounding waters, red-footed boobies are able to track zones of prey availability located in areas of enhanced primary production. Searching is probably favoured by the presence of sub-surface predators that chase prey to the surface. The foraging strategy of this tropical sulid appears to differ extensively from that of temperate or polar seabirds whose prey distribution and availability are more predictable.
\end{abstract}

KEY WORDS: Sula sula · GPS · Satellite tracking · Mozambique Channel $\cdot$ Chlorophyll concentration · Sea-level height anomalies

\section{INTRODUCTION}

The way predators forage and distribute themselves with respect to the environment depends on the distribution, abundance and predictability of prey (Bell 1991). In the oceans, marine predators are generally assumed to be searching for prey in a featureless environment, but very little information is available on the foraging strategies used by these predators because of the difficulty of studying marine animals in the open ocean. Seabirds are exceptions because they are large and conspicuous predators that can be studied from research vessels or from land-based sites during the breeding period. Physical processes are known to affect the distribution of plankton (Wolanski \& Hamner 1988, Francks 1992) and recent studies have shown that seabirds respond to fronts, shelf edges or upwelling where productivity is enhanced or where prey are passively concentrated (review in Hunt et al. 1999). Seabirds distribute themselves according to 
these physical mechanisms and can concentrate in large numbers at these specific foraging sites. Furthermore, the preferences exhibited by individual birds for particular foraging sites suggest that birds can remember the location of particular oceanographic features; however, the predictability of oceanic processes and prey aggregations is dependent upon the spatial and temporal scales considered (Hunt \& Schneider 1987, Schneider 1993), and is probably only high at mesoscale (100s of kilometres) or larger scales (Hunt et al. 1999). At smaller scales, birds must actively search for prey patches that are sparse and unpredictably located, and often adopt specific foraging strategies based on spotting the behaviour of congeners or other predators, and on restricting their searches to small size sectors once these cues have been detected (review in Nevitt \& Veit 1999).

In polar and temperate waters, many ship-based studies on the factors affecting the distribution and abundance of birds at sea (see review in Hunt et al. 1999), and land-based studies using newly developed miniaturised loggers and telemetry systems (e.g. Guinet et al. 1997, Nel et al. 2001, Hyrenbach et al. 2002), have demonstrated the importance of physical scale-dependent processes on the foraging ecology of seabirds and the diversity of foraging strategies that are used (Shealer 2001). In tropical waters, there have been much fewer ship-based studies of seabirds (Bailey 1967, Pocklington 1979, Ballance et al. 1997, Spear et al. 2001, Jaquemet et al. 2004) and almost no landbased studies using telemetry systems; yet, the tropical marine environment constitutes an interesting case study for comparative purposes to test hypotheses about the importance of scale-dependent processes on the distribution of marine predators or the evolution of foraging strategies. Indeed, in tropical waters, production is overall low compared to temperate and polar waters (Longhurst \& Pauly 1987), and the distribution and abundance of seabird prey is believed to be more unpredictable than in colder waters (Ashmole 1971); thus, it is often hypothesised that these extreme conditions should have led to the evolution of specific energy-efficient foraging strategies in tropical seabirds (Flint \& Nagy 1984, Ballance \& Pitman 1999). In addition, the constraints imposed by the marine environment on foraging are particularly strong during breeding, when seabirds must commute between the colony and feeding grounds. At this time, the proximity of prey aggregations to colonies or the ability of seabirds to forage efficiently and to reach distant prey patches at low energetic costs become critical; thus, selection for improving the foraging efficiency of seabirds has probably been a major evolutionary force resulting in a wide variety of foraging strategies and morphological adaptations (Ashmole \& Ashmole 1967,
Pennycuick 1987, Spear \& Ainley 1998, Ballance \& Pitman 1999). In addition, rather than solely physical processes (e.g. prey aggregation at fronts and convergences), biological processes, in particular the association with sub-surface predators such as tuna or dolphins, appear to be of overwhelming importance in the foraging success of tropical seabirds (Au \& Pitman 1986, Ballance et al. 1997, Jaquemet et al. 2004). This is particularly the case for piscivorous species associated with surface-dwelling tunas in areas of strong vertical thermal gradients (e.g. thermocline depth) in the tropical Pacific (Spear et al. 2001).

The family Sulidae includes the large gannets and the smaller boobies. Whereas the 3 species of gannets are temperate or cold-water foragers, boobies include 6 species that breed at tropical latitudes (Nelson 1978). The red-footed booby Sula sula (RFB) is the smallest of the Sulidae. Most authors consider the RFB as the most pelagic booby (Nelson 1978, Schreiber et al. 1996). Since small clutch size is often related to pelagic habits in seabirds (Lack 1968, Weimerskirch 2001), the strictly 1 egg clutch of RFBs, compared to the other species with 1 to 4 eggs per clutch, reinforces the suggestion of pelagic habits of this species; however, no study has yet determined the actual foraging range of breeding birds. It can be expected that the extreme foraging adaptations and strategies that may have evolved in tropical seabirds should be particularly apparent in a species such as the RFB.

The aim of this study was to precisely describe the way a tropical central-place seabird forages for food and to examine whether this foraging strategy differs from those of closely related temperate species, or from other temperate or polar seabirds. We were particularly interested to test whether the low productivity may promote specific ways of foraging, and how tropical species deal with more unpredictable prey patches. We studied RFBs breeding on Europa Island in the Mozambique Channel using a suite of recently developed miniaturised loggers, which allowed us to reconstruct the foraging ecology of this tropical seabird.

\section{MATERIALS AND METHODS}

The study was conducted on Europa Island $\left(22.3^{\circ} \mathrm{S}\right.$, $40.3^{\circ} \mathrm{E}$ ) in the Mozambique Channel (Fig. 1) between 18 August and 30 September 2003. Approximately 2800 to 3800 pairs of RFBs breed on Europa Island, with all colonies located in the dry Euphorbia stenoclada forest of the northern part of the island (Le Corre \& Jouventin 1997). RFBs are seasonal breeders at Europa, with most egg-laying occurring between July and October (Le Corre 2001); thus, during the course of our study, most pairs were incubating or brooding 


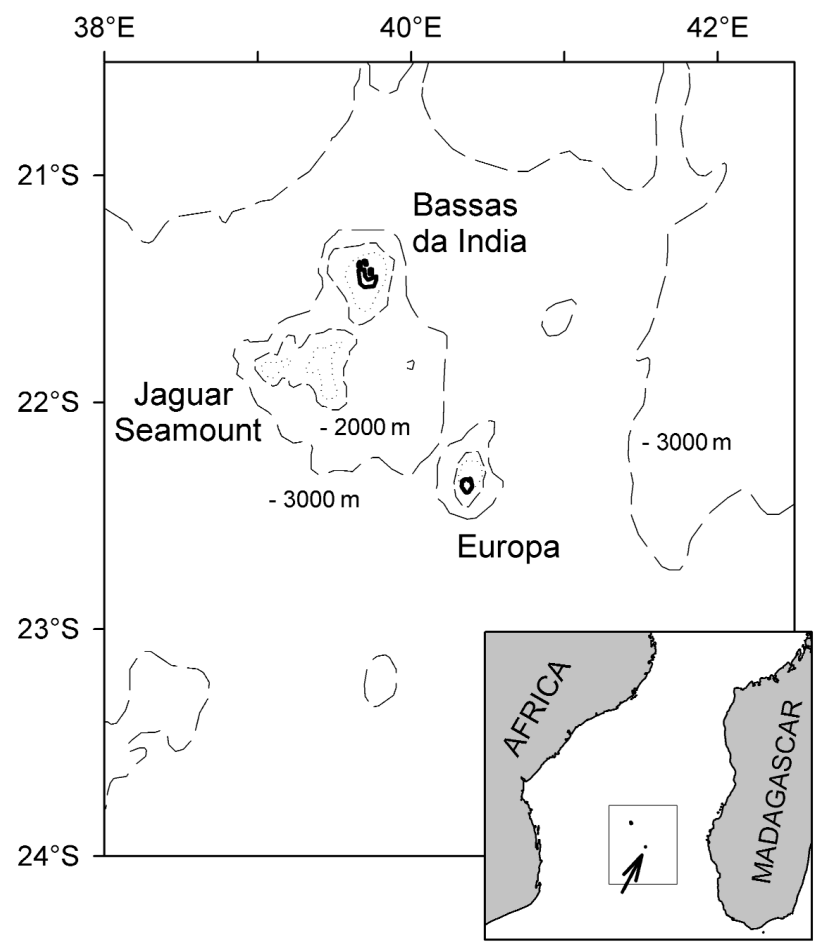

Fig. 1. Map of the central Mozambique Channel showing the location of Europa Island and surrounding seamounts. The arrow on the inset shows the location of Europa Island

young chicks. RFBs show several plumage morphs that vary extensively according to localities (Nelson 1978). In the Indian Ocean, most extant colonies contain birds of the white morph, except at Europa where $98.5 \%$ of the birds are of the white-tailed brown morph and $1.5 \%$ of the white morph (Le Corre 1999).

Our main study plot included about 50 nests built on trees at 1 to $6 \mathrm{~m}$ from the ground. At the beginning of the study period, each nest was numbered with a plastic tag and the colony mapped, and in each nest, 1 bird of each pair was marked with a yellow patch of picric acid on the white tail using a sprayer without handling the birds. This yellow patch allowed us to rapidly identify birds at a distance. The study colony was monitored 3 to 4 times per day (at dawn and dusk, i.e. at 06:00 and 17:45 $h$, and once or twice in the middle of the day) to determine which member of the pair was in the nest and, thus, to infer departure and return of birds fitted with loggers. To attach loggers, birds were captured by hand for those accessible from the ground, or with a $6 \mathrm{~m}$ telescopic fishing pole fitted with a nylon noose for the birds nesting higher in the trees. When captured for the first time, birds were measured (culmen length, beak width and maximum height, wing length), weighed and banded with a stainless steel band. When recaptured for logger recovery, they were only weighed.
To study movements, 16 birds were fitted for 2 to 5 successive foraging trips (46 foraging trips in total) with Platform Terminal Transmitters PTT 100 Argos satellite transmitters (Microwave telemetry) weighing $20 \mathrm{~g}$. The PTTs transmitted continuously, with a repetition time of 60 to $90 \mathrm{~s}$. We used service+ from the Argos system that uses 3 satellites for location of animals (Argos 1989) and allowed us to obtain $14.4 \pm 2.2$ locations per day. In addition, we fitted 16 different individuals for a single trip with a GPS receiver with an integrated antenna and a $1 \mathrm{Mb}$ flash memory operated by a rechargeable battery (Newbehavior; Steiner et al. 2000) recording at $10 \mathrm{~s}$ intervals. The loggers were sealed into small polyethylene bags. The overall weight of the device and its waterproof package was $32 \mathrm{~g}$. The PTTs and GPS loggers were taped under the 3 central tail feathers using Tesa tape.

To study activity patterns, we used $6 \mathrm{~g}$ activity recorders (IMV2, Immersion Monitor Version 2, Ferguson Manufacturing) that record the presence of seawater across electrodes to infer immersion time. The sampling rate was 1 recording $\mathrm{s}^{-1}$. The activity recorders were fitted on a metal leg band with tape, and precisely measured the time of landing or diving on water and of taking off, and thus the duration of bouts spent on the water and in flight.

As RFBs are relatively small seabirds (mass 780 to $1050 \mathrm{~g}$ ), only 1 type of logger was fitted on each bird (representing a maximum of 3 to $4 \%$ of the bird body mass for the GPS) except for activity recorders that were deployed together with PTTs to 12 individuals ( 2.5 to $3.3 \%$ of the bird body mass in total) to derive the location of landings. No deleterious effects of loggers were noted; birds returned to their nest every evening just as birds not fitted with loggers.

We used all location types provided by the Argos system, but the locations were filtered following Weimerskirch et al. (1993), with a maximum flight speed of $95 \mathrm{~km} \mathrm{~h}^{-1}$ for RFBs, based on the GPS recording (see 'Results'). We also discarded locations too closely separated in time, by less than $10 \mathrm{~min}$, discarding the less accurate one following the classification provided by Argos, because the distance that a bird could travel during this short time is that of the inherent error of the locations. Data were then treated using a custom software package ('Diomedea', D. Filippi, see Weimerskirch et al. 2000 for details and other examples of its usage). This software takes into account the time spent on the water and in flight by activity logger-equipped birds, so that the real mean speed of travel between successive satellite locations can be estimated as well as the location of landings, based on the assumption that 
birds fly in a straight line between locations. It calculates a location every $10 \mathrm{~s}$ so that data from the GPS and the PTTs can be pooled for the estimates of foraging areas. To estimate foraging areas, we pooled the location obtained from the GPS and the PTTs. We used the fixed kernel method (Worton 1995) and the least square algorithm (Seaman \& Powell 1996). We estimated contour levels including 10 to $90 \%$ of the locations distribution (Wood et al. 2000, Hyrenbach et al. 2002).

Locations of active foraging or foraging bouts were derived from periods when birds were sitting on the water as recorded by the activity recorders fitted with PTTs, or for speeds lower than $10 \mathrm{~km} \mathrm{~h}^{-1}$ for the GPS recording (Weimerskirch et al. 2005). Isolated short landings were not considered as foraging bouts. For each foraging trip, we estimated a destination heading as the bearing between the colony and the first zone of active foraging (or the most distant point of a trip when no foraging patch was detected). To measure how consistent birds were in their foraging destinations, we measured the difference in bearing between successive trips. Wind direction at the departure of foraging trips was measured each morning from the meteorological station located $100 \mathrm{~m}$ from the study colony.

Sea-surface height anomalies and associated geostrophic current strengths were obtained from the AVISO data base of the CLS Physical Oceanography Division (http://www.aviso.oceanobs.com/). Sea-surface chlorophyll concentrations were derived from the SeaWiFS Local Area Coverage (LAC) ocean colour data, acquired and processed at the IRD-SEAS tracking station in La Réunion (under agreement with NASA). Individual swaths were assembled to cover the entire Mozambique Channel and moving averages were calculated with a $7 \mathrm{~d}$ period to reduce the proportion of cloudy pixels. The original spatial resolution (1 km) was degraded to $2 \mathrm{~km}$. Data were then mapped with SURFER 7.0 (Anonymous 1999) using the kriging interpolator with a linear variogram, assuming no nuggets effects (Barnes 1991). The study period was divided into 2 periods with similar numbers of tracks: 25 August to 12 September 2003 and 13 to 28 September 2003.

Statistical analyses were performed with STATISTICA 6.0. As the individuals were tracked for several successive trips, to avoid pseudoreplication problems, we analysed the data on the characteristics of the trips using mixed-model ANOVAs. Speed, range, distance covered, activity etc. were the dependent variables; categories (period, stage etc.) were entered as fixed factors; and individual was considered as a random factor. Values are given as average $\pm 1 \mathrm{SD}$.

\section{RESULTS}

The duration of foraging trips was $10.1 \pm 1.9 \mathrm{~h}$ during the incubation (range 4.8 to 12.5 ) and $5.0 \pm 2.0 \mathrm{~h}$ (range 1.1 to $7.3 \mathrm{~h}$ ) during the brooding period (mixed ANOVA $\left.F_{1,32}=86.0, \mathrm{p}<0.0001\right)$. During incubation, birds departed from the colony early in the morning between 06:00 and 08:00 $\mathrm{h}$, and returned in the afternoon before dusk, and occasionally at night. During brooding, departure times were spread throughout the day. Day length was on average $12.5 \mathrm{~h}$ during the study period (range 12.2 to $12.8 \mathrm{~h}$ ).

\section{Activity}

During their foraging trips, birds spent $66.7 \pm 14.9 \%$ (range 36.0 to 94.8 ) of the time in flight and the remaining time sitting on the water or diving. The proportion of time spent on the water was similar during incubation and brooding (mixed ANOVA, $F_{1,22}=0.02, \mathrm{p}=0.933$ ). Most flight time occurred during the morning and evening, with almost half of the time sitting on the water occurring in the middle of the day (Fig. 2). Landing and take-offs peaked in the afternoon (Fig. 2). Birds landed on the sea (or dived) on average $29.6 \pm 12.2$ times $^{-1}$ (range 8 to 65), at similar rates during brooding and incubation (mixed ANOVA, $F_{1,12}=0.305, \mathrm{p}=0.895$ ).
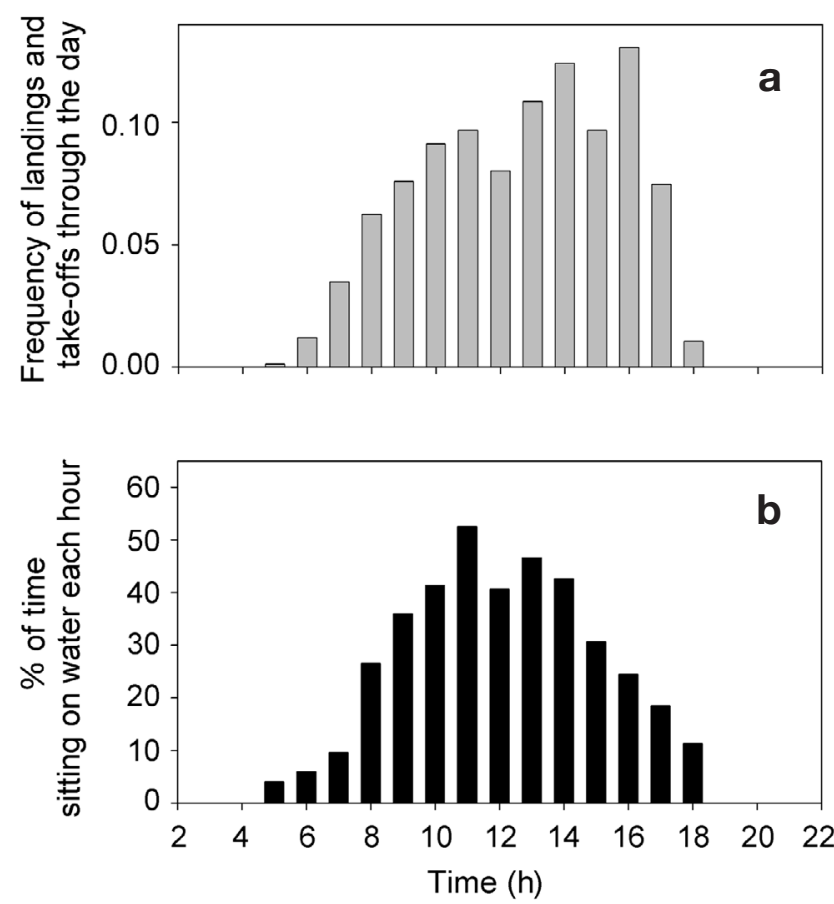

Fig. 2. Sula sula. (a) Frequency distribution of sea landings and take-offs throughout the day. (b) Percentage of the time spent on the water each hour 


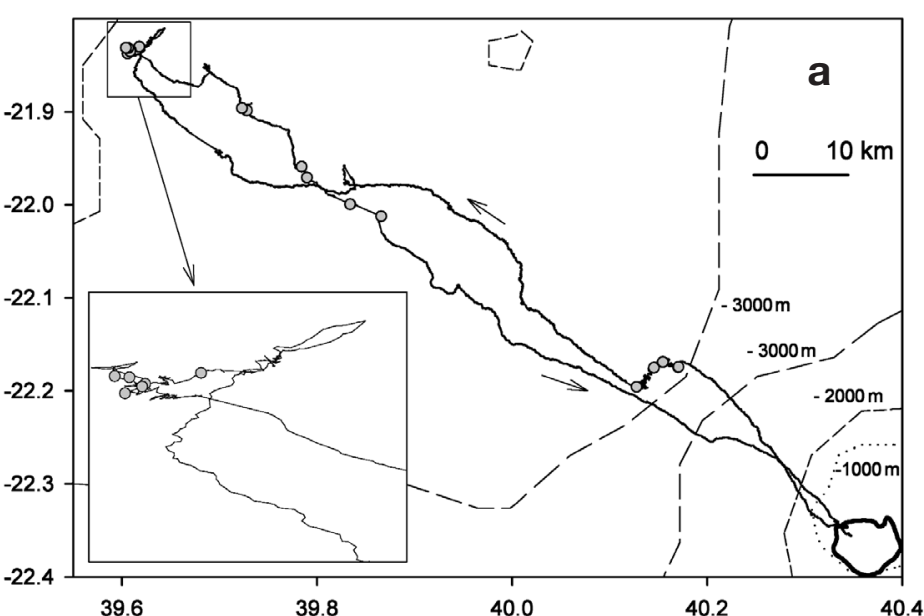

Fig. 3. Sula sula. Foraging trips of 2 RFBs fitted with GPS recording at a frequency of 1 location every $10 \mathrm{~s}$, with an enlargement of an area with foraging activity. Grey dots: speed $<10 \mathrm{~km} \mathrm{~h}^{-1}$, i.e. foraging activity (landing, diving etc.); arrows: flight direction. (a) Return directional trip; (b) looping trip

\section{Foraging movements}

When leaving the colony, birds headed directly for foraging grounds. Most trips (71.7\%) were directional return trips with fairly parallel, and close outward and return paths, the remaining were loop shaped (Fig. 3a,b, respectively). The median speed recorded by GPS was $38 \mathrm{~km} \mathrm{~h}^{-1}$, with a maximum speed of $95 \mathrm{~km} \mathrm{~h}^{-1}$. The trips were typically divided into 3 phases. First, the bird moved rapidly away from the colony, at a high and constant speed, with a linear or curvilinear route. Second, the bird started to change direction and speed continuously, suggestive of foraging activity. During this time, the birds landed on the water, or dived, frequently. There were between 1 and 4 (average $2.2 \pm 1.0$ ) foraging bouts per trip. Finally, the bird returned to the colony, at a more constant flight speed, and with a relatively straight route.

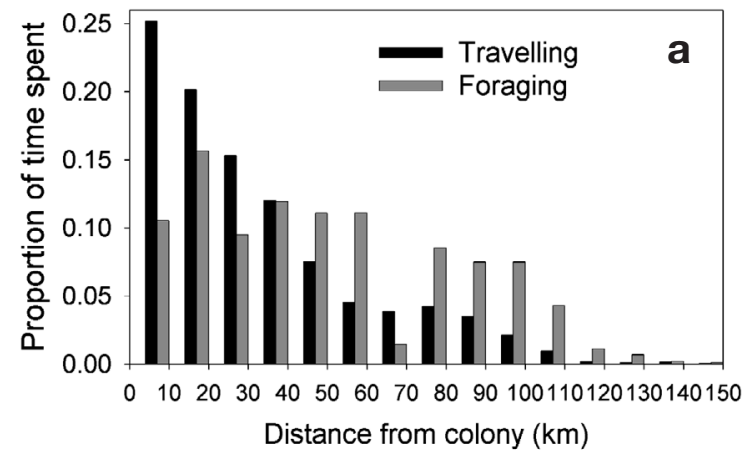

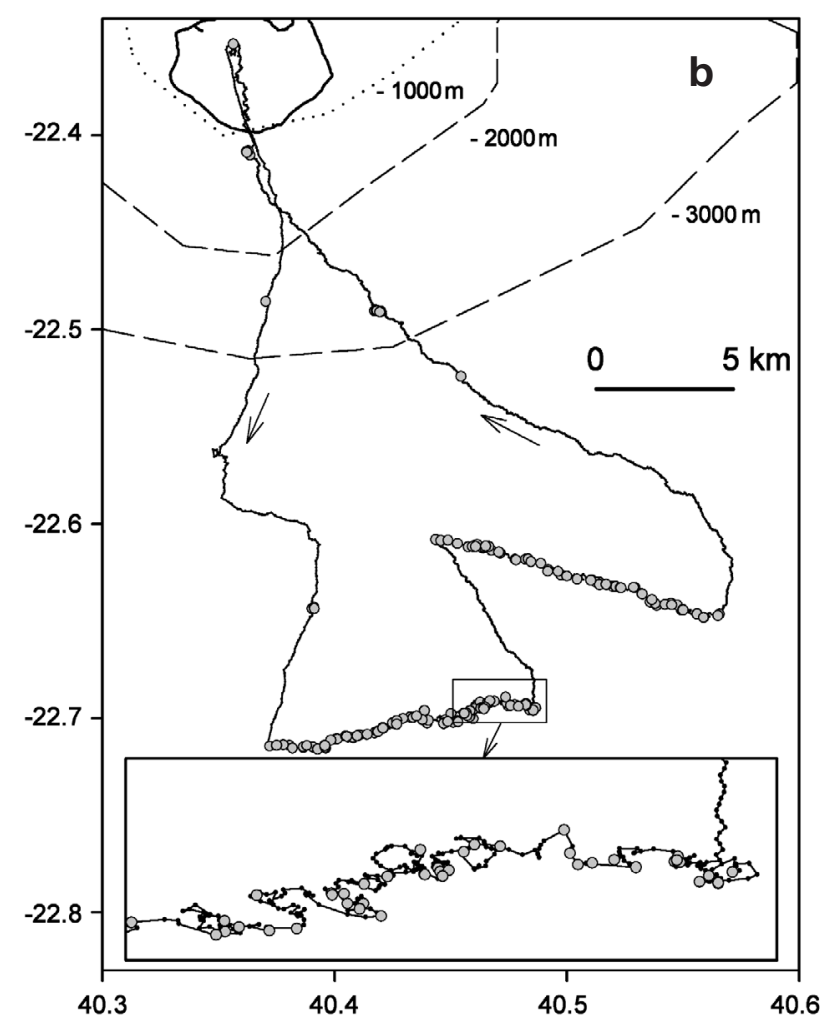

During incubation, birds forage at an average range of $67.2 \pm 34.0 \mathrm{~km}$ from the colony (range 12 to $148 \mathrm{~km}$ ). During brooding, the range decreased to $39.2 \pm 28.5 \mathrm{~km}$ (range 10 to $114 \mathrm{~km}$ ) (mixed ANOVA, $\left.F_{1,24}=5.2, \mathrm{p}=0.035\right)$. The distance covered was $169.6 \pm 82.2 \mathrm{~km}$ during incubation and $117.3 \pm$ $65.5 \mathrm{~km}$ during brooding (mixed-model ANOVA, $\left.F_{1,24}=4.3, \mathrm{p}=0.0575\right)$. The duration of foraging trips was related to the maximum foraging range (maximum range $=5.4212$ duration $-1.0555, \mathrm{R}^{2}=0.4179$, $\mathrm{n}=55, \mathrm{p}<0.001)$. Foraging activity generally took place within the most distant section of the foraging trip (Fig. 4).

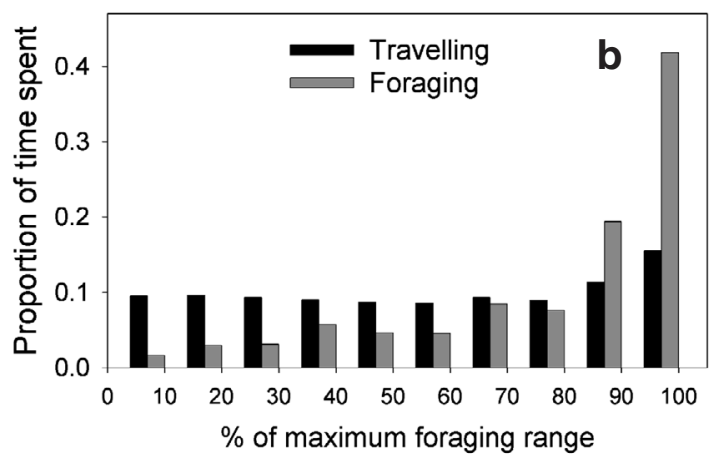

Fig. 4. Sula sula. Proportion of the foraging trip spent travelling and foraging (a) by distance from the colony and (b) by the percentage of the maximum foraging range reached during each trip 

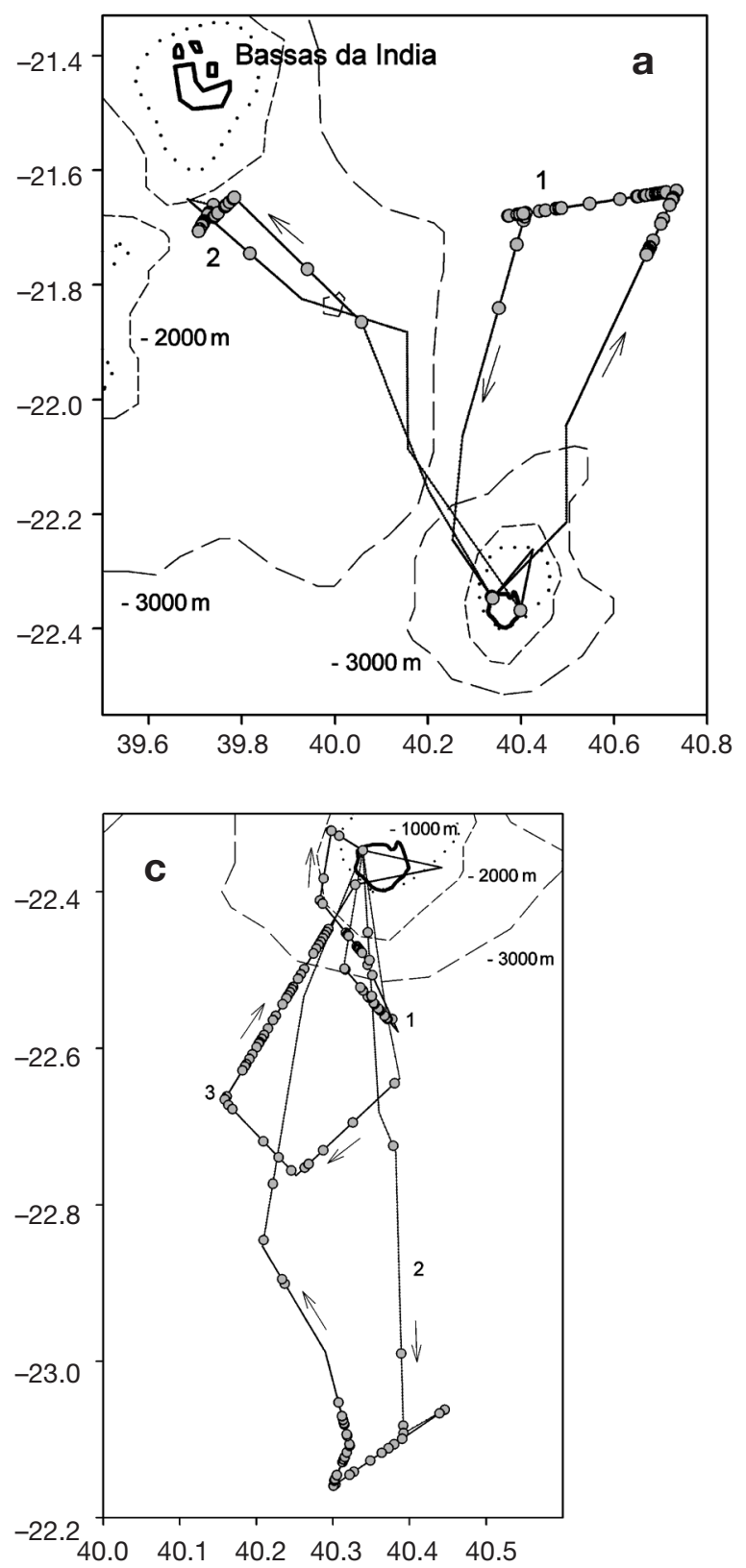

Fig. 5. Sula sula. Foraging trips of 3 RFBs fitted with a satellite transmitter and an activity recorder: (a) 2 and (b,c) 3 successive trips. Grey dots: estimated location of landings; Arrows: flight directions. The numbers indicate the order of the successive trips

None of the 13 individuals tracked for at least 2 successive trips returned to the same area to forage (Fig. 5); however, in $70.4 \%$ of the 27 pairs of successive trips by the same individual, birds headed in the same direction (angular difference between successive flight direction $<30^{\circ}$ ). Although birds often flew in the same direction, they moved at various ranges and, thus, had their foraging activities in different areas (Fig. 5).

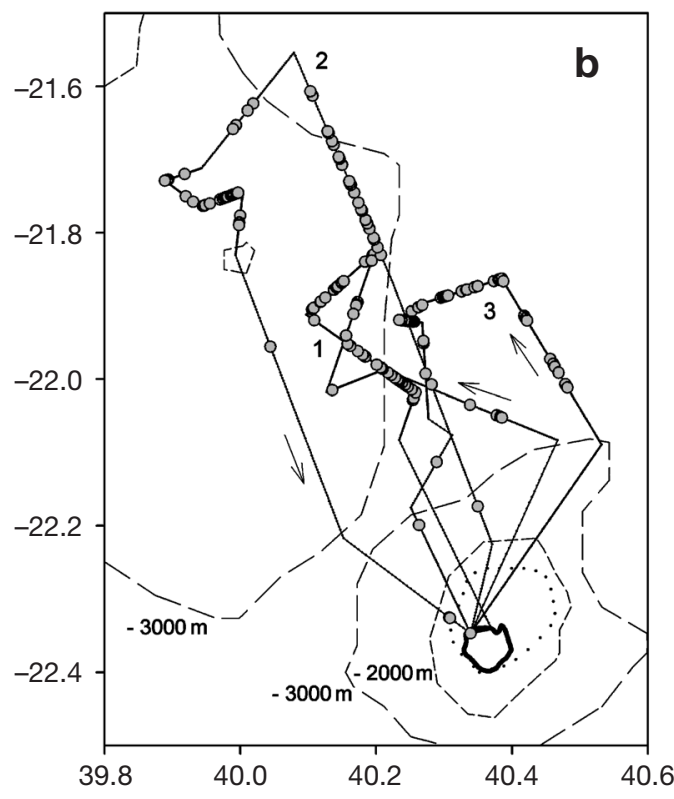

Foraging zone

Birds did not head in all directions evenly when moving away from the colonies (Fig. $6, \chi^{2}{ }_{3}=17.4, p<0.001$, $\mathrm{n}=56$ ); the majority of trips were directed toward the west, south and north of the island, with very few trips to the east. Trips during the first part of the study were mostly directed to the north and south, whereas those during the second part were directed to the west (Fig. 6, $\left.\chi_{3}^{2}=14.1, \mathrm{p}=0.003\right)$. Wind direction was similar during the 2 periods $\left(\chi_{2}^{2}=1.7, \mathrm{p}=0.522\right)$, blowing mainly from the south (59\% of the days) and, to a lesser extent, from the east $(27.9 \%)$ and north $(13.1 \%)$. The main foraging

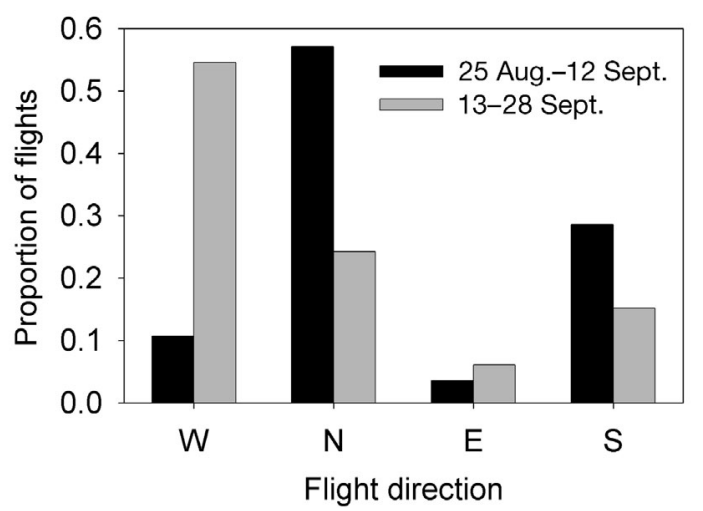

Fig. 6. Sula sula. Frequency distribution of foraging trips' departure directions during the first and second part of the study period (23 August to 12 September, 13 to 28 September, respectively) 

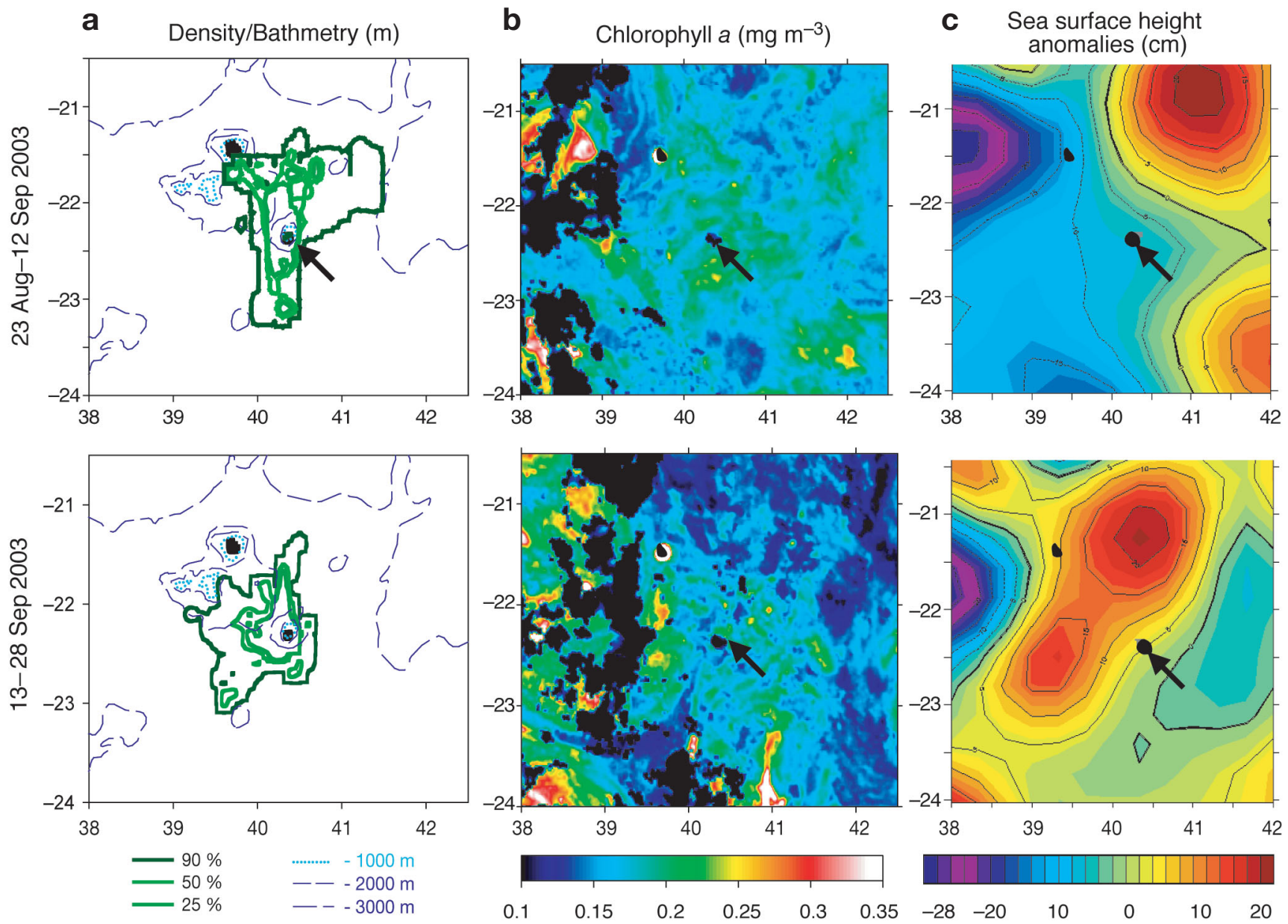

Fig. 7. Sula sula. Changes between the first (23 August to 12 September, upper panels) and second (13 to 28 September, lower panels) periods of the study in (a) the foraging areas of RFBs as shown by density contour plots (in green) from kernel estimates of the amount of time spent at sea, with bathymetry in blue, in (b) the distribution of chlorophyll concentration, cloud cover in black, and (c) sea-surface height anomalies. Arrow indicates location of Europa Island. Bassas da India is the island to the north-west of Europa

areas were concentrated to the south and north during the first part of the study, and to the west of Europa during the second part (Fig. 7).

\section{Oceanographic conditions and primary production}

The central part of the Mozambique Channel is a zone of deep waters and since there is no shelf (water depth $<200 \mathrm{~m}$ ) around Europa, or in the vicinity around the Bassas da India bank, birds forage solely over deep oceanic waters (Fig. 1). In this sector, strong cyclonic and anticyclonic eddies move southward and are associated with strong geostrophic currents (Fig. 7c). The ocean productivity, as measured by satellite chlorophyll concentration, was low overall (average $0.165 \mathrm{mg}$ chlorophyll $\mathrm{m}^{-3}$ ), but patchy in space and time (Fig. 7b). During the course of the study, the oceanographic conditions changed extensively around Europa (Fig. 7). Zones of higher productivity (>0.2 mg chlorophyll $\mathrm{m}^{-3}$ ) occurred in the foraging range of RFBs, but changed in intensity and in location over time, probably transported by geostrophic currents and/or mixed by a strong gale that occurred between 14 and 17 September (Fig. 7b).

Within the range of $\mathrm{RFBs}$, the foraging zones appeared to be related to the location of zones of higher primary production. During the first part of the study period, when production was high within the foraging range of RFB, to the south and north of Europa, most birds moved to the south or north (Fig. 7a,b). During the second part of the study, most birds moved to the west where ocean productivity appeared higher (Fig. 7a,b). 


\section{DISCUSSION}

\section{Foraging range}

Traditionally, the RFB has been considered to be the most pelagic of all boobies (Nelson 1978, Schreiber et al. 1996). Our study shows that breeding RFBs left their colonies for a maximum of $12.5 \mathrm{~h}$, a bit longer than the duration of daylight at the latitude of Europa in winter (12 h); thus, their foraging range is limited primarily by the duration of their available foraging time. With an average flight speed of $38 \mathrm{~km} \mathrm{~h}^{-1}$, a $12.5 \mathrm{~h}$ return flight would give a potential maximum range of $237 \mathrm{~km}$. The actual maximum range recorded in this study was only $148 \mathrm{~km}$. This discrepancy is due to the time required for foraging, i.e. to actively search and follow feeding opportunities, forage and dive. If we subtract the average proportion of time spent on the water during a trip $(33.3 \%)$, the maximum theoretical range is $158 \mathrm{~km}$, i.e. a value very close to that observed. An oceanographic cruise (ECOTEM-9 cruise, IRD-Thetis) conducted around Europa at the same time as our study indicates that the maximum distance at which RFBs were observed was $157 \mathrm{~km}$, confirming the limited range of the breeding population, but also of the nonbreeding birds (Jaquemet et al. in press). Previous ship-based studies conducted in the Indian Ocean only recorded RFBs in the vicinity of breeding colonies (Bailey 1967).

The only other tracking study on boobies, using radio tracking, gives an estimated foraging range of $65 \mathrm{~km}$ from the colony for masked boobies Sula dactylatra (Anderson \& Ricklefs 1987). The much larger northern gannet Morus bassanus forages at a maximum range of $540 \mathrm{~km}$ (mean $232 \mathrm{~km}$ ) with trips lasting 13 to $84 \mathrm{~h}$ (Hamer et al. 2000). Cape gannets Morus capensis forage at maximum distances of $242 \mathrm{~km}$ (mean $85 \mathrm{~km}$ ), with trips lasting 1.5 to $48 \mathrm{~h}$ (Grémillet et al. 2004); thus, the foraging range in the larger temperate species is extended by their ability to spend the night at sea, in addition to their higher flight speed. The only locality where RFBs foraging trips are longer than $1 \mathrm{~d}$ is the Galapagos, where birds leave the colony for several days during severe El Niño (Nelson 1978); however, being absent from the nest for several days does not necessarily mean that birds are spending the night at sea, as we have shown for Europa birds. They could land at night either on their breeding island or on other islands of the Galapagos archipelago.

\section{Foraging strategies in tropical waters}

During the study period, RFBs were mainly feeding on flying fishes (Family Exocaetidae) and flying squids
(Family Ommastrephidae) (M. Le Corre unpubl. data), i.e. similar prey as in other localities (Nelson 1978, Harrison et al. 1983, Schreiber et al. 1996). RFBs do not dive deeper than $2.4 \mathrm{~m}$ (Weimerskirch et al. 2005). They can only catch prey that either naturally occur near the surface, or that are chased to the surface. In the Pacific Ocean (Au \& Pitman 1986, Ballance et al. 1997), RFBs are generally observed feeding in association with sub-surface predators such as tuna, or dolphins, that chase prey to the surface, making them available to seabirds.

The foraging strategy of RFBs was to leave the colony rapidly in a particular direction; flight directions at departure were not related to the prevailing wind direction but to the flight direction of the previous day. Birds spent most of their time in flight during the outward part of the flight. In the middle of the day, birds became more active by landing and taking off frequently. The change in activity in the middle of the day is probably related to birds having reached prey patches after a period of commuting, rather than to the higher availability of prey at this particular time of the day as shown in long range frigatebirds that feed on the same prey mainly in the morning and evening (Weimerskirch et al. 2004). In areas of high activity, presumably a prey patch, birds are extremely active. This increased activity with continuous landing and take offs, often associated with changes in flight direction and flight speed has been described as Area Restricted Search (ARS, Kareiva \& Odell 1987). In pelagic seabirds, ARS seems to be a common strategy (Nevitt et al. 1995, Veit \& Prince 1997); once a bird has detected prey, it changes its flight route from very directional to very erratic. By increasing its turning rate, the forager remains within the vicinity of the prey. In RFB, ARS is clearly apparent in the GPS tracks (Fig. 3a). Observations at sea around Europa suggest that this behaviour is often that of birds feeding over sub-surface predators (Jaquemet et al. in press). Another strategy, not as typical as ARS, is when RFB continuously change direction, but still continue on a linear trajectory on a large scale with numerous brief landings, resulting in a reduced travelling speed of only 5 to $10 \mathrm{~km} \mathrm{~h}^{-1}$ (Fig. 3b). This strategy may correspond to birds following sub-surface predators such as tuna schools that travel at speeds of 4 to $7 \mathrm{~km} \mathrm{~h}^{-1}$ (Marsac \& Cayré 1998) and perhaps prey on large organisms such as flying fish. An energetic study carried out in the Pacific on RFB, with activity budgets similar to those of RFB from Europa, indicates that the cost of foraging may be particularly low (Ballance 1995). This is surprising in view of the extremely high activity, but may be due to the extensive use of wind by RFB to reduce flight costs. 


\section{Foraging zones in relation to oceanography}

In temperate and polar regions, seabirds are well known to associate with fairly predictable foraging zones where prey are available in association with specific physical features such as fronts, seamounts or shelf edges (Hunt et al. 1999). As RFBs are central place foragers with a restricted range, they have a limited choice of foraging habitats, particularly compared to species that move widely, such as frigatebirds that were tracked at distances greater than $600 \mathrm{~km}$ from Europa when breeding (Weimerskirch et al. 2004). As there is no shelf around Europa, RFB cannot reach productive zones associated with shelf areas and are, therefore, strictly oceanic foragers. Within the foraging range of RFB, the extensive Bassas da India and Jaguar sea mounts (Fig. 1) may constitute a zone of upwelling, but this is not apparent when examining the distribution of primary production from SeaWifs imagery. Seamounts are known to be favourable foraging grounds for tuna schools, which tend to aggregate above them throughout the tropical oceans (Fonteneau 1991). The tracked RFBs did not preferentially forage above, or in the wake of these seamounts that are located $120 \mathrm{~km}$ from Europa, i.e. at the limit of the foraging range of the species. The Mozambique Channel is well known for a persistent field of mesoscale anticyclonic gyres very slowly moving southward (Schouten et al. 2003). The cyclonic vortices associated with these eddies can enhance productivity through horizontal transport by geostrophic current or through upwelling (Quartly \& Srokosz 2004). Due to their southward movement, the location of the eddies constitutes an unpredictable oceanographic feature (Fig. 7). Furthermore, their intensity is not constant but cyclic and consequently induces a high degree of variability in the magnitude of the upwelled waters responsible for enhancing the phytoplanktonic production. In addition, surface mixing due to strong gales may also influence the level of primary production at the surface. Ocean productivity around Europa is, therefore, fairly low and its distribution is heterogeneous, changing within as little time as a week (Fig. 7).

Vessel-based surveys in the eastern Pacific Ocean indicate that RFB flocks only occur in the vicinity of breeding grounds, located in the eastern part of the Eastern Tropical Pacific (Ballance et al. 1997). These authors attributed the RFB distribution to the higher productivity of the surface waters $\left(0.17 \mathrm{mg} \mathrm{m}^{-3}\right.$ of chlorophyll) and to the proximity of their breeding grounds. The Mozambique Channel waters around Europa had an average chlorophyll concentration of $0.165 \mathrm{mg} \mathrm{m}^{-3}$ during the study period, comparable to the oceanic waters of the eastern Pacific inhabited by RFBs. Although water productivity may also be impor- tant in determining the presence of boobies, our study suggests that the proximity of breeding grounds constrains the oceanic range of breeding and, possibly, non-breeding, birds. Within their foraging range, RFBs appear to be attracted by zones of enhanced productivity. These zones may concentrate zooplankton and their associated predators such as flying fish and squid, which are themselves preyed upon by tuna and marine mammals that chase them to the surface.

\section{Foraging in an unpredictable environment for ephemeral prey patches}

The oceanographic conditions surrounding Europa suggest that RFBs forage in a zone of generally low primary productivity, with some patches of enhanced productivity whose distribution is mobile and location is unpredictable. Successive trips by the same bird indicate that individuals do not return to the same foraging area from one trip to the next; however, birds generally head in the same direction as on the previous day until they encounter a prey patch, which is found at a variable range from the colony from one day to the next. The direction taken is probably related to a higher predictability at a mesoscale of the location of zones of high productivity; however, because zones of higher productivity can disappear rapidly or shift location advected by geostrophic currents, such zones may only be spatially predictable within a period of a few days, forcing the birds to regularly change flight direction. The rule of thumb may be that individuals select a particular direction according to the foraging success of the previous day. If unsuccessful, RFB should change direction, either randomly, or according to the behaviour of other birds. Since foragers generally leave the island in small groups, they could also follow other birds that had a good foraging success the previous day, but such a hypothesis based on the existence of an information centre (Ward \& Zahavi 1973) has yet to be demonstrated. Such foraging decisions only concern mesoscale features that are temporarily available, but the way they are able to head to the most productive patches has to be evaluated (see for example Davoren et al. 2003).

After choosing a particular heading unrelated to wind direction, birds encounter prey patches at various distances from the colony. At a coarse scale (kilometres to 100 s of metres), foraging birds probably locate prey patches by the activity of sub-surface predators close to the surface (Au \& Pitman 1986). At greater distances, they probably locate feeding opportunities by local enhancement (see review by Nevitt \& Veit 1999), i.e. by observing the behaviour of congeners or other surface-feeding seabirds such as the superabundant 
sooty terns. Such behaviour may result in a network foraging (Wittenberger \& Hunt 1985), which is probably an efficient way of detecting ephemeral resources. Our results suggest that feeding bouts in association with tunas and marine mammals may be ephemeral, lasting only a few minutes to several 10s of minutes as recorded by the bouts of activity. We do not know whether the brevity is due to the brevity of the event itself, or whether in some cases the bird leaves the feeding opportunity when enough prey have been captured. Since feeding opportunities can occur several times during the course of a foraging trip, it is likely that they are ephemeral for seabirds.

In the Galapagos, radio-tracked masked boobies appear to change flight direction from one day to the next, suggesting that prey location was also unpredictable (Anderson \& Rickelfs 1987). In contrast, in temperate and polar waters, many species return to the same areas from one foraging trip to the next (see review in Hunt et al. 1999). Hamer et al. (2001) found very similar bearings and distances travelled on successive foraging trips for the temperate northern gannets, suggesting a predictable spatial distribution of prey patches in the North Atlantic. Cape gannets concentrate their foraging effort in zones of coastal upwelling in the Benguela Current (Grémillet et al. 2004). This difference, and the relation between foraging and productivity, is consistent with the idea that marine habitats are less predictable in tropical than in temperate regions. We can hypothesise that this critical difference leads to contrasted foraging strategies between the 2 environments. Further comparative studies have to be carried out to elucidate how different environmental conditions have led to the evolution of contrasted life histories between tropical and other marine environments.

Acknowledgements. We thank the Direction Régionale de l'Environnement (DIREN) of Ile de la Réunion for financial support; the Préfet de la Réunion and the Direction of Météo France for authorisations and help to work on Europa; the Forces Armées de la Zone Sud de l'Océan Indien (FAZSOI) for transport to and logistical support on Europa. We thank M. Slepoukha (IRD-US Espace) for extracting the SeaWiFS data, L. Ballance, D. Hyrenbach and 2 anonymous referees for their extensive helpful comments and suggestions.

\section{LITERATURE CITED}

Anderson DJ, Ricklefs RE (1987) Radio-tracking masked and blue-footed boobies (Sula spp.) in the Galàpagos Islands. Nat Geogr Res 3:152-163

Anonymous (1999) SURFER 7: contouring and 3D surface mapping for scientists and engineers. Golden Software Inc., Golden, CO

Argos (1989) Guide to the Argos System. Argos CLS, Toulouse

Ashmole NP (1971) Seabird ecology and the marine environ- ment. In: Farner DS, King JR (eds) Avian biology, Vol 1. Academic Press, New York, p 223-286

Ashmole NP, Ashmole MJ (1967) Comparative feeding ecology of seabirds of a tropical oceanic island. Peabody Museum of Natural History, Yale University, Bulletin 24, Peabody Museum of Natural History, New Haven, CT

Au DWK, Pitman RL (1986) Seabird interactions with dolphins and tuna in the eastern tropical Pacific. Condor 88: 304-317

Bailey RS (1967) The pelagic distribution of sea-birds in the western Indian Ocean. Ibis 110:493-519

Ballance LT (1995) Flight energetics of free-ranging redfooted boobies (Sula sula). Physiol Zool 68:887-914

Ballance LT, Pitman RL (1999) Foraging ecology of tropical seabirds. In: Adams NJ, Slotow RH (eds) Proceeding of the 22nd International Congress, Durban. Birdlife South Africa, Johannesburg, p 2057-2071

Ballance LT, Pitman RL, Reilly SB (1997) Seabird community structure along a productivity gradient: importance of competition and energetic constraint. Ecology 78: 1502-1518

Barnes R (1991) The variogram sill and the sample variance. Math Geol 23:673-678

Bell WJ (1991) Searching behaviour. Chapman \& Hall, London

Davoren GK, Montevecchi WA, Anderson JT (2003) Search strategies of a pursuit-diving marine bird and the persistence of prey patches. Ecol Monogr 73:463-481

Flint EN, Nagy KA (1984) Flight energetics of free living sooty terns. Auk 101:288-294

Fonteneau A (1991) Seamounts and tuna in the tropical Atlantic. Aquat Living Resour 4:13-25

Franks PJS (1992) Phytoplankton blooms at fronts:patterns, scales and physical forcing mechanisms. Rev Aquat Sci 6: 121-137

Grémillet D, Dell'Omo G, Ryan PG, Peters G, Ropert-Coudert Y, Weeks SJ (2004). Offshore diplomacy, or how seabirds mitigate intra-specific competition: a case study based on GPS tracking of cape gannets from neighbouring colonies. Mar Ecol Prog Ser 268:265-279

Guinet C, Khoudil M, Bost CA, Durbec JP, Georges JY, Mouchot M, Jouventin P (1997) Foraging behaviour of satellite tracked king penguins in relation to sea-surface temperatures obtained by satellite telemetry at Crozet archipelago: a study during three austral summers. Mar Ecol Prog Ser 150:11-20

Hamer KC, Phillips RA, Wanless S, Harris MP, Wood AG (2000) Foraging ranges, diets and feeding locations of gannets in the North Sea: evidence from satellite telemetry. Mar Ecol Prog Ser 200:257-264

Hamer KC, Phillips RA, Hill JK, Wanless S, Wood AG (2001) Contrasting foraging strategies of gannets (Morus bassana) at two North Atlantic colonies: foraging trip duration and foraging area fidelity. Mar Ecol Prog Ser 224:283-290

Harrison CS, Hida TS, Seki MP (1983) Hawaiian seabird feeding ecology. Wildl Monogr 85:1-71

Hunt GL Jr, Schneider DC (1987) Scale dependent processes in the physical and biological environment of marine birds. In: Croxall JP (ed) Seabirds: feeding biology and role in marine ecosystems. Cambridge University Press, Cambridge, p 7-41

Hunt GL, Mehlum F, Russell RW, Irons D, Decker MB, Becker PH (1999) Physical processes, prey abundance, and the foraging ecology of seabirds. In: Adams NJ, Slotow RH (eds) Proceeding of the 22nd International Congress, Durban. Birdlife South Africa, Johannesburg, p 2040-2056

Hyrenbach KD, Fernañdez P, Anderson DJ (2002) Oceano- 
graphic habitats of two sympatric North Pacific albatrosses during their breeding season. Mar Ecol Prog Ser 233: 283-301

Jaquemet S, Le Corre M, Weimerskirch H (2004) Seabird community structure in a coastal tropical environment: importance of natural factors and fish aggregating devices (FADs). Mar Ecol Prog Ser 268:281-292

Jaquemet S, Le Corre M, Marsac F, Potier M, Weimerskirch H (in press) Foraging habitats of the seabird community of Europa Island (Mozambique Channel). Mar Biol

Kareiva P, Odell G (1987) Swarms of predators exhibit 'preytaxis' if individuals predators use area-restricted search. Am Nat 130:233-270

Lack D (1968) Ecological adaptations for breeding in birds. Methuen, London

Le Corre M (1999) Plumage polymorphism of red-Footed boobies (Sula sula) in the western Indian Ocean: an indicator of biogeographic isolation. J Zool 249:411-415

Le Corre M (2001) Breeding seasons of seabirds at Europa Island (southern Mozambique Channel) in relation to seasonal changes in the marine environment. J Zool 254: 239-249

Le Corre M, Jouventin P (1997) Ecological significance and conservation priorities of Europa Island (Western Indian Ocean), with special reference to seabirds. Terre et Vie Rev Ecol 52:205-220

Longhurst AR, Pauly D (1987) Ecology of tropical ocean. Academic Press, San Diego, CA

Marsac F, Cayré P (1998) Telemetry applied to behaviour analysis of yellowfin tuna (Thunnus albaceres, Bonnaterre 1788) movements in a network of fish aggregating devices. Hydrobiologia 371/372:155-172

Nel DC, Lutjeharms JRE, Pakhomov EA, Ansorge IJ, Ryan PG, Klages NTW (2001) Exploitation of mesoscale oceanographic features by grey-headed albatrosses Thalassarche chrysostoma in the southern Indian Ocean. Mar Ecol Prog Ser 217:15-26

Nelson JB (1978) The Sulidae: gannets and boobies. Oxford University Press, Oxford

Nevitt G, Veit RR (1999) Mechanisms of prey-patch detection by foraging seabirds. In: Adams NJ, Slotow RH (eds) Proceeding of the 22nd International Congress, Durban. Birdlife South Africa, Johannesburg, p 2072-2082

Nevittt GA, Veit RR, Kareiva PM (1995) Dimethyl sulphide as a foraging cue for Antarctic Procellariiform seabirds. Nature 376:680-682

Pennycuick CJ (1987) Flight of seabirds. In: Croxall JP (ed) Seabirds: feeding ecology and role in marine ecosystems. Academic Press, New York, p 43-62

Pocklington R (1979) An oceanographic interpretation of seabird distributions in the Indian Ocean. Mar Biol 51:9-21

Quartly GD, Srokosz MA (2004) Eddies in the southern Mozambique Channel. Deep-Sea Res II 51:69-83

Schneider DC (1993) Scale dependent spatial dynamics: marine birds in the Bering Sea. Biol Rev 68:579-598

Schouten MW, de Ruijter PM, van Leeuwen PJ, Ridderinkhof $\mathrm{H}$ (2003) Eddies and variability in the Mozambique Channel. Deep-Sea Res II 50:1987-2003

Schreiber EA, Schreiber RW, Schenk GA (1996) Red-footed

Editorial responsibility: Otto Kinne (Editor-in-Chief), Oldendorf/Luhe, Germany booby (Sula sula). In: Poole A, Gill F (eds) The birds of North America, No. 241. The Academy of Natural Sciences, Philadelphia, PA, and The American Ornithologist's Union, Washington, DC

Seaman DE, Powell RA (1996) An evaluation of the accuracy of kernel density estimators for home range analysis. Ecology 77:2075-2085

Shealer DA (2001) Foraging behavior and food of seabirds. In: Schreiber EA, Burger J (eds) Biology of marine birds. CRC Press, Boca Raton, FL, p 137-177

Spear LB, Ainley DG (1998) Morphological differences relative to ecological segregation in petrels (Family: Procellariidae) of the Southern Ocean and tropical Pacific. Auk 115:1017-1033

Spear LB, Ballance LT, Ainley DG (2001) Response of seabirds to thermal boundaries in the tropical Pacific: the thermocline versus the Equatorial Front. Mar Ecol Prog Ser 219: 275-289

Steiner I, Bürgi C, Werffeli S, Dell'Omo G, Valenti P, Tröster G, Wolfer DP, Lipp HP (2000) A GPS logger and software for analysis of homing in pigeons and small mammals. Physiol Behav 71:589-596

Veit RR, Prince PA (1997) Individual and population level dispersal of black-browed and grey-headed albatrosses in response to Antarctic krill. Ardea 85:129-134

Ward P, Zahavi A (1973) The importance of certain assemblages of birds as 'information-centres' for food-finding. Ibis 115:517-534

Weimerskirch H (2001) The demography of seabirds and its relationship with the marine environment. In: Schreiber EA, Burger J (eds) Biology of marine birds. CRC Press, Boca Raton, FL, p 115-135

Weimerskirch H, Salamolard M, Sarrazin M, Jouventin P (1993) Foraging strategy of wandering albatrosses through the breeding season: a study using satellite telemetry. Auk 110:325-342

Weimerskirch H, Guionnet T, Martin J, Shaffer SA, Costa DP (2000) Fast and fuel efficient? Optimal use of wind by flying albatrosses. Proc R Soc Lond B 267:1869-1874

Weimerskirch H, Le Corre M, Jaquemet S, Potier M, Marsac F (2004) Foraging strategy of a top predator in tropical waters: great frigatebirds in the Mozambique Channel. Mar Ecol Prog Ser 275:297-308

Weimerskirch H, Le Corre M, Ropert-Coudert Y, Kato, Marsac F (2005) The three dimensional flight of red-footed boobies: adaptions to foraging in a tropical environment. Proc R Soc Lond 272:53-60

Wittenberger JF, Hunt GL Jr (1985) The adaptive significance of coloniality in birds. Avian Biol 8:2-43

Wolanski E, Hamner WM (1988) Topographically controlled fronts in the ocean and their biological influences. Science 241:177-181

Wood AG, Naef-Daenzer P, Prince PA, Croxall JP (2000) Quantifying habitat use in satellite tracked pelagic seabirds: application of the kernel estimation to albatross locations. J Avian Biol 31:278-286

Worton BJ (1995) Using Monte Carlo simulation to evaluate kernel-based home range estimators. J Wildl Manag 59: $794-800$

Submitted: May 13, 2004; Accepted: September 7, 2004

Proofs received from author(s): February 16, 2005 